\title{
Investor's Disposition Error at Emerging Market: Evidence for Experiential and Rational Thinking Styles
}

\author{
Perminas Pangeran
}

Business Faculty, Duta Wacana Christian University, Jl. Dr Wahidin Sudirohusodo, 5-25, Yogyakarta - Indonesia, 55224

\author{
Doi:10.5901/mjss.2015.v6n5p313
}

\begin{abstract}
This study aims to examine the role of two information processing styles toward investor's disposition errors. This experimental study used a full factorial design $2 \times 2 \times 2$ (two decision outcomes: negative and positive, two types of action: inaction (hold stock) and action (sell stock), two information processing styles: rational and experiential styles. The subjects in this experiment consisted of 181 participants. The experimental results conclude several important findings. First, there was a significant interaction of information processing styles, types of action, and decision outcomes in shaping degree of participant's satisfaction/regret in investment decisions. Interestingly, when the decision outcome was negative (actual loss) and type of action was to hold losing stock, degree of regret was higher for subjects who were in an experiential styles than rational thinking styles. Likewise, when decision outcome was positive (missed loss) and type of action was to hold stocks, degree of satisfaction was higher for subjects who were in an experiential style rather than rational thinking styles. Second, the result of this study indicated that the emotion of satisfaction/regret was more predominant on subjects who were in an experiential thinking style than a rational thinking style. This result revealed that disposition error was greater on subjects who were in an experiential style than a rational thinking styles.
\end{abstract}

Keywords: Disposition Error, Regret, Rational and Experiential Styles.

\section{Introduction}

Behavioral finance researchers frequently caution investors against disposition error, a problem characterized by selling winning stocks too early and holding losing stocks too late. Although their advice seems obvious, a number of studies document a strong tendency for individual investors to exhibit this behavior (e.g., Shefrin \& Statman, 1985; Odean, 1998; Krishnan \& Booker, 2002). Admittedly, disposition error has financial consequences, which would be detrimental to the wealth of investors (Frazzini, 2006; Todd, 2012). This psychological bias occurs systematically and repeatedly in the capital markets (Nofsinger, 2002). Certainly, this phenomena deviates from and can not be explained by the assumption of standard financial theory.

Various studies have been offering diverse explanations regarding its cause (Talpsepp, 2011; Richard \& Lei, 2012, Tehrani \& Gharehkoolchian, 2012). However, most of the extant research emphasizes more on aspects of cognitive bias and ignores the emotional aspects of the investors. In fact, investors' emotional aspect plays an important role in explaining their disposition error (Nofsinger, 2002; Ackert, Church, \& Deaves, 2003; Fogel \& Berry, 2006). Therefore, this is a future research opportunity with an emphasis on the emotional aspects of investors in an emotion-based investment decision model.

In this study, the emotion-based investment decision model is based on the perspective of regret theory, known as decision-justification theory (Connolly \& Zeelenberg, 2001; Connolly, 2004). Decision-justification theory postulates two core components of decision-related regret, one associated with the evaluation of the outcome, the other with the feeling of self-blame for having made a poor choice. A person regrets when he or she chooses the wrong option and the decision he or she made was, in retrospect, unjustified. This unjustified decision is related to the style of an information processing. In line with this explanation, the emotional effects can lead to behavior biases due to the type of action, a negative outcome, and information processing styles. In this study, the three elements are the important issues to be discussed further in explaining the phenomena of investors' disposition error

Theoretical support has also recognized the importance of the role of decision-maker's individual difference or personality traits, such as an information processing style in decision-making process (Gul, 1984; Epstein, Pacini, \& Heier, 1996; Chui, 2001). Gul (1984) states that understanding of decision-maker's personality traits may be able to guide the design of the information processing system toward more effective user decisions. Moreover, extant research results gave the signal that emotions of regret may lead to different behavioral biases on the two information processing styles, 
experiential and rational thinking styles (Hon-snir et al., 2012). In this case, Epstein et al. (1996) Cognitive-Experiential Self-Theory (CEST) proposes that the two styles operate in an independent, parrallel, and interactive manner, and together they contribute to behavior. Moreover, empirical support have signalled that psychological biases increased greatly under time pressure, when opportunity for analytic deliberation was reduced (Slovic et al., 2004). Although two thinking styles have a potential impact on behavior, but until now no study has attempted to examine the role of experiential and rational thinking styles in explaining the phenomena of investor's disposition error. This gap became a main motivation for this study.

Given the explanation above, this study focuses on factors shaping the investor's disposition error in terms of the perspective of regret theory and cognitive-experiential self-theory. Specifically, the purpose of the study is to examine the degree of regret or satisfaction as a result of the type of action (sell stocks versus hold stocks), decision outcomes (negative versus positive), and information processing styles (rational and experiential thinking styles). Through testing of these behavioral models, this study is expected to have implications on the development of theories and models of investment policies and practices in Indonesia. Firstly, the result of this study is expected to contribute in the form of a model of behavioral finance with an emphasis on the emotional aspect. Secondly, the financial practitioners should recognize emotional biases in theirs and in others, as well as understand the various reasons for mistake-making, as well as avoid the pitfalls caused by human error.

\section{Literatur Review and Hypothesis Development}

\subsection{Literatur Review}

\subsubsection{Explanation of Regret Theory and Phenomena of Disposition Error}

Some researchers have attempted to examine the role of regret emotion in explaining disposition error. Nevertheless, among those are researchers who have not come to a final conclusion concerning why these investor's disposition errors occur. Likewise, explanation of the regret theory regarding the antecedents and its consequences of regret emotion on investor's disposition error is still under debate. Loomes and Sugden (1982) and Bell (1982) incorporate the emotion of regret in the theory of choice. The regret theory predicts that one would feel sad if a decision outcome is worse than the result of the different alternative. Thus, one would avoid the various options that made it a possibility due to bad decisions.

Furthermore, Shefrin and Statman (1985) state that the fear of regret encourage investors to postpone the realization of the loser, while the desire to gain a sense of pride encourage investors to realize profits too early. Therefore, investors tend to avoid actions that cause feelings of regret and look for actions which result to a sense of pride. Feelings of fear of regret encourage investors to postpone the realization of losers. Meanwhile, the search for a sense of pride causes a person to realize profits immediately. This also explains why market participants are losers but still justify their actions.

Meanwhile, based on the perspective of decision-justification theory, Connolly and Zeelenberg (2002) state that emotion of regret is as a result of a bad outcome and bad decisions. Thus, investors may regret worse outcomes compared to standard; and the decision they made was, in retrospect, unjustified. Based on the second component, this theory predicts that an investor experiences more intense emotions of regret due to choosing the wrong option, and gets a bad outcome in an important decision. Consistent with the predictions of the regret theory, this model focuses on two factors on the antecedents of regret emotion, namely outcomes (positive vs. negative) and the type of action (omission and commission bias) and their consequences on the level of investor's disposition error. Previous studies have examined the effect of the type of actions and of the decision outcomes on the emotions of regret. However, extant research about the factors that explains the phenomena of investor's disposition error is yet to be concluded.

\subsubsection{Explanation of Cognitive-Experiential Self-Theory (CEST) and Phenomena of Disposition Error}

Likewise, the present study base on the perspective of Cognitive-Experiential Self-Theory (Epstein et al.,1996) to expand its explanation of the phenomena of investor's disposition error. Pacini and Epstein (1999) states that what people are experiencing are the outcomes of two different information-processing systems, rational dan experiential.

The experiential system operates automatically and preconsciously according to heuristic rule. It is concretive, associationistic, holistic, primarily nonverbal and closedly related to affect. Meanwhile, the rational system is deliberative, primarily verbal, conscious, and relatively affect free. Two information processing styles together contribute to behavior, 
with their relative contributions varying from none at all to complete dominance by either one of the styles (Pacini, Muir \& Epstein, 1998; Pacini \& Epstein,1999).

In the context of investment, rational thinking style leads investors to affect free and they tend to understand the risks as analysis. In contrast, the experiential style leads investors to affect heuristic and they tend to comprehend the risk as feelings. Experiential thinking style, such as affect heuristic, can cause an investor trapped in a psychological bias. This psychological bias can plunge the investor to omission and commission biases. These biases reflect investor's disposition error. Empirical support has proven that psychological biases increased greatly under time pressure, when opportunity for analytic deliberation was reduced (Slovic et al., 2004). Consistent with the explanation and prediction of the theory, this research extends antecedent of regret on two information-processing styles, that is experiential and rational thinking styles. Thus, the interaction of the type of outcome and type of action is also conjectured to change on two information processing styles: experiential and rational thinking style.

\subsection{Hypothesis Development}

Connolly and Zeelenberg, 2001 and Connolly, 2004 propose a new regret theory, known as decision-justification theory. They suggest that regret comprises of two components: an evaluation of the realized outcome compared to some alternative (bad-outcome regret) and a feeling of self-blame for making a poor choice (bad-decision regret). This theory predicts that a person experiences more intense of regret, in important decisions, due to chooses a bad option and uses a poor decision process. Specifically, bad-decision regret may be attributed to two aspects, namely types of action (Kahneman \& Tversky, 1982) and two information processing systems (Epstein et al., 1996).

The results of previous studies showed that emotion of regret was closely related to the disposition error (Shefrin \& Statman, 1985; Fogel \& Berry, 2006; Yahyazadehfar, Ghayekhloo, \& Sadeghi, 2010; Tehrani \& Gharehkoolchian, 2012). Intense regret may be experienced by a person in important decisions, when they receive a bad outcome, choose a wrong option, and when decision they made was, in retrospect, unjustified (Connolly \& Zeelenberg, 2002; Connolly, 2004). Based on this explanation, it can be concluded that the investor's satisfaction or regret is a function of the decision outcomes, type of action, and decision process.

Following the perspective of cognitive-experiential self-theory (CEST, the decision process can be done based on the experiential and rational thinking style considerations. Rational system operates on slower processing, oriented toward delayed action, the conscious level and intentional, analytical, and relatively affect free. On the contrary, experiential system is considered a rapid information processing oriented toward immediate action, and closely related to affect. Due associated with affective, as a result, a person who has experiential style can lead to the wrong decision. Specifically, the experiential system may cause a number of biases in investment decisions.

As described ealier, experiential thinking style that is closely related to affect heuristic may cause a person to be at a psychological bias. This psychological bias can plunge the investor to the disposition error. Empirical support indicates that the psychological bias increased greatly under time pressure, when opportunity for analytic deliberation was reduced (Slovic et al., 2004). Meanwhile, in the style of rational thought, which is relatively free of affect, less likely trapped in a psychological bias. Investor has opportunity for analytic deliberation. In this case, it is expected that level of investor's disposition error may change under experiential system and analytical rational system condition. As implied by the theories, investor's disposition error is expected to be greater in an experiential thinking style than rational thinking style. Based on the explanation of the theory and empirical results as discussed above, the following hypotheses are posited as below:

$\mathrm{H} 1$. There is an interaction between information processing styles, types of action, and decision outcomes in shaping degree of subject's satisfaction/regret in investment decisions.

$\mathrm{H} 1 \mathrm{a}$. When the decision outcome is negative and type of action is hold losing stock, degree of regret is higher for subjects who are in an experiential style than a rational thinking style.

$\mathrm{H} 1 \mathrm{~b}$. When decision outcome is positive and type of action is to sell stocks, degree of satisfaction is higher for subjects who are in an experiential than rational style.

H2. The emotion of satisfaction/regret is more predominant on subjects who are in an experiential style than a rational thinking style. 


\section{Method}

\subsection{Subject}

The subjects of this study were undergraduate students from a Study Group of Capital Market (SGCM) enrolled in finance and accounting classes. Participants had taken at least one course in financial management, investment and portfolio analysis, and capital market. Subjects were then randomly assigned to each treatment condition between subjects. Testing hypotheses used factorial analysis of variance models. The experiment was conducted in a classroom setting with 181 participants. This is in accordance with the advice of at least 5-25 participants per treatment condition (Myers \& Hans, 2001: 217).

\subsection{Experimental Design}

This experimental design in this study used a factorial design $2 \times 2 \times 2$ (two decision outcomes: negative and positive, two types of action: no action (hold stocks) and acting (sell stocks), two information processing styles: rational and experiential thinking styles). Types of decision outcomes (positive vs negative) consist of (1) a real gain (positive), (2) missed loss (positive), (3) missed gain (negative), and (4) a real loss (negative). Decision outcomes, the type of action, and information processing styles are between-subjects variable.

\subsection{Treatment Combinations and Measurement}

This experiment basically applies the framework of Fogel and Berry (2006), but with with two modifications. First, unlike in previous studies, the measurement scale for the dependent variable based on a seven-point Likert scale ranges from 1 to 7 (1= regret very much and 7= very satisfied). Secondly, this study takes into account personality traits, two styles for processing information, a rational and experiential thinking styles. Meanwhile, measurements on the experiential and rational thinking styles based on Pacini and Epstein's (1999) instrument.

This study used the independent variable, action (hold versus sell), decision outcomes (positive versus negative), and two styles for processing information: rational and experiential thinking styles. In this study, the experimental condition consisted of eight treatment combinations. Eight treatment conditions is a combination of three independent variables, namely; two decision outcomes: negative and positive, two types of action: not taking action (hold stocks) and taking action (sell stocks), and two styles for processing information, an experiential and rational thinking styles. These factors are between-subjects variable. Thus, each group received one experimental treatment condition.

Therefore, before entering the four treatmen conditions (2 decision outcomes: negative and positive; two types of actions: hold stocks and sell stocks), the subjects were asked to respond to the scale of personality traits, two styles of processing information (experiential and rational). Participant's information processing styles was measured on 20 items of the experiential thinking styles, as developed by Pacini and Epstein (1999). Each items in the experiential thinking styles measured on a 7- point likert-type scale, ranging from $1=$ never to $7=$ always.

The purpose of the individual differences test is to classify participants into two groups, namely experiential thinking style and rational thinking style. This study used arithmetic mean for the grouping of participants' information processing style in rational and experiential style, according to whether the information processing style scores of participants, each of which is below or above this average. As such, in the group of the experiential style, each participant was randomly assigned to four treatment conditions. As described above, in the group of the rational style, each participant was randomly assigned to the other four treatment conditions.

The dependent variables are the degree of emotional intensity of regret or satisfaction. Degree of regret or satisfaction may lead to investor's disposition error behavior. In addition, the degree of regret is derived from the type of action and decision outcomes of the investment decisions. In accordance with the treatment conditions, each participant was asked to read a case of investment decision of the following form.

Imagine that last year you purchased some stock in Company "GHR" at IDR 15,000 a share. After it fell in value to IDR 11,000 a share, you decided to sell/thought about selling, but decided to hold. You found out that this morning that the current price is IDR 27,000/IDR 6,000 a share.

After reading the above case, the subjects were asked to rate their regret or satisfaction on their investment decisions using a five-point likert scale ranging from 1 to 7 ( $1=$ regret very much and $7=$ very satisfied). Finally, participants were also asked to respond to several questions in check manipulations. They were asked whether realize the type of decision outcomes (positive and negative) and the type of action (acting and not acting). 


\section{Results and Discussion}

\subsection{Characteristics of Subjects, Manipulation Checks, and The Assumption of Factorial Analysis of Variance}

The purpose of this experimental study was to examine the role of emotions of regret on investors' disposition error in investment decisions. This study invited 181 undergraduate students from Business Faculty, consisting of 87 males and 94 females as participants through the Study Group of Capital Markets. The characteristics of participants from the eight experimental conditions were matched. The matching was based on sex (gender), age, majors, and experience of the subject. However, these results indicated that the effect of the subject characteristic was constant in each experimental condition. After matching, participants were randomly assigned to each experimental condition. Therefore, the distribution of participants in each experimental condition is presented in Table 1 below.

Table 1. Distribution of Participants in each Experimental Condition

\begin{tabular}{lccc}
\hline \multirow{2}{*}{ Information Processing Styles } & Types of Action & \multicolumn{2}{c}{ Decision Outcomes } \\
\cline { 3 - 4 } & & $\begin{array}{c}\text { Negative } \\
\text { (Actual Loss or Missed Gain) }\end{array}$ & $\begin{array}{c}\text { Positive } \\
\text { (Actual Gain or Missed Loss) }\end{array}$ \\
\hline \multirow{2}{*}{ Experiential Thinking Style } & Sell Stocks & $1 / 4=22$ & $3 / 4=21$ \\
& Hold Stocks & $4 / 4=30$ & $2 / 4=23$ \\
\hline \multirow{2}{*}{ Rational Thinking Style } & Sell Stocks & $1 / 4=26$ & $3 / 4=26$ \\
& Hold Stocks & $4 / 4=17$ & $2 / 4=16$ \\
\hline
\end{tabular}

Manipulation check was conducted to ensure that participants understand the manipulation as defined in the research instruments. Manipulation check was performed based on two factors, namely; the type of action and decision outcomes. Overall, the manipulation check showed that majority of participants perceived manipulation as contemplated in the research instrument.

\subsection{Results}

Table 2 reports descriptive data on eight treatment conditions. This data reflects the degree of regret experienced by a participant after receiving treatment condition. Based on the degree of regret/satisfaction, participants who experience and fear of regret would lead to their disposition errors in investment decisions. Meanwhile, the testing result of data normality with the Kolmogorov-Smirnov approach ( $p$-value $>a=0.05$ ) was fulfilled for each treatment condition. Likewise, based on the levene's test ( $p$-value $>a=0.05)$, the homogeneity of variance is met for each treatment conditions.

Table 2. Descriptive Data for each Treatment Combination

\begin{tabular}{|c|c|c|c|c|c|c|c|c|}
\hline \multirow{2}{*}{ Information Processing Styles } & \multirow{2}{*}{ Types of Actions } & \multirow{2}{*}{ Decision Outcomes } & \multirow{2}{*}{ Treat-ment Combination } & \multicolumn{5}{|c|}{ Degree of Regret/Satisfaction } \\
\hline & & & & $\mathrm{N}$ & Mean & SD & SW & Levene test \\
\hline 1 & 2 & 3 & 4 & 5 & 6 & 7 & 8 & 9 \\
\hline \multirow{4}{*}{ Experiential Style } & \multirow{2}{*}{ Sell Stocks } & Negative (Missed Gain) & $1 / 4 e$ & 22 & 2.36 & 1.136 & 0.96 & 2.20 \\
\hline & & Positive (Actual Gain) & $3 / 4 \mathrm{e}$ & 21 & 4.81 & 0.873 & 0.93 & $(0.15)$ \\
\hline & \multirow{2}{*}{ Hold Stocks } & Negative (Actual Loss) & $4 / 4 \mathrm{e}$ & 30 & 1.57 & 0.774 & 0.94 & 1.06 \\
\hline & & Positive (Missed Loss) & $2 / 4 \mathrm{e}$ & 23 & 6.39 & 0.839 & 0.93 & $(0.31)$ \\
\hline \multirow{4}{*}{ Rational Thinking Style } & \multirow{2}{*}{ Sell Stocks } & Negative (Missed Gain) & $1 / 4 \mathrm{r}$ & 26 & 1.69 & 0.679 & 0.97 & 2.15 \\
\hline & & Positive (Actual Gain) & $3 / 4 r$ & 26 & 4.58 & 0.987 & 0.92 & $(0.15)$ \\
\hline & \multirow{2}{*}{ Hold Stocks } & Negative (Actual Loss) & $4 / 4 r$ & 17 & 1.88 & 0.928 & 0.95 & 0.10 \\
\hline & & Positive (Missed Loss) & $2 / 4 r$ & 16 & 5.50 & 1.211 & 0.94 & $(0.76)$ \\
\hline
\end{tabular}

Overall, according to Table 2, the degree of regret/satisfaction is more predominant in participants who are in the experiential thinking style than rational thinking style. This result indicates that the level of disposition error is greater in participants who are in experiential thinking style than rational thinking style.

Testing of the hypotheses were conducted using a three-way factorial analysis of variance, $2 \times 2 \times 2$. In a factorial analysis of variance, the first step was to test the interaction effect (Keppel, 1982: 209). If the interaction effect is significant, then less attention should be paid to the main effects. Analysis tends to focus on a search for the specific conditions contributing to the significant interaction. The results of the factorial analysis of variance are presented in Table 
3.

Table 3. Results of the Factorial Analysis of Variance

\begin{tabular}{lccccc}
\hline Source & Type III Sum of Squares & df & Mean Square & F & Sig. \\
\hline Corrected Model & $592.359 \mathrm{a}$ & 7 & 84.623 & 99.710 & 0.000 \\
Intercept & 2250.402 & 1 & 2250.402 & 2651.621 & 0.000 \\
Information Processing Style (IPS) & 5.946 & 1 & 5.946 & 7.007 & 0.009 \\
Type of Action & 9.785 & 1 & 9.785 & 11.529 & 0.001 \\
Outcome & 515.277 & 1 & 515.277 & 607.144 & 0.000 \\
IPS * Type of Action & .293 & 1 & .293 & .345 & 0.558 \\
IPS * Outcome & 1.603 & 1 & 1.603 & 1.889 & 0.171 \\
Type of Action * Outcome & 26.304 & 1 & 26.304 & 30.993 & 0.000 \\
IPS * Type of Action * Outcomes & 7.357 & 1 & 7.357 & 8.669 & 0.004 \\
\hline
\end{tabular}

a. R Squared $=.801$ (Adjusted R Squared $=.793$ )

Based on Table 3, the result of the analysis of the three-way factorial analysis of variance show that the interaction of information processing style, type of action, and decision outcomes was significant $(F=8.669$ and $p$-value $=0.004)$. This result indicates that there is a significant interaction between information processing style, type of action, and decision outcomes in shaping the degree of participant's satisfaction/regret in investment decisions. This result supports the hypothesis $\mathrm{H}_{1}$. Also, there is a significant interaction effect between the type of action and decision outcomes $(\mathrm{F}=$ 30.993; $p$-value $=0.000)$, whereas no significant interaction of the type of action and information processing type $(F=$ $0.345 ; p$-value $=0.558)$, as well no interaction of the information processing style and decision outcomes $(F=1.889 ; p$ value $=0.171)$. Meanwhile, there is a main effect on the decision outcome (positive and negative) $(F=607.144 ; p$-value $=$ 0.000 ) and the type of action (sell/hold) $(F=11.529 ; p$-value $=0.001)$ and information processing styles (experiential and rational style) $(F=7.007 ; p$-value $=0.009)$, all significant at $\alpha=0.01$.

Figure 1 shows the ordinal interaction of factors on rational thinking styles. Therefore, in the rational thinking style, the main effect can be interpreted independently of the interaction of two factors, namely the type of action and decision outcomes. Table 3 and Figure 1 show that when participants have rational thinking style and decision outcome is negative, the degree of regret is higher on selling stocks (1.69) than holding stocks (1.88). Likewise, when the participants have rational thinking style and decision outcome is positive, the degree of satisfaction is greater for holding (5.50) than selling gaining stocks (4.58). Interestingly, the high degree of satisfaction indicates that the level of participant's disposition error is greater when holding the stock.

\section{Rational Thinking Style}

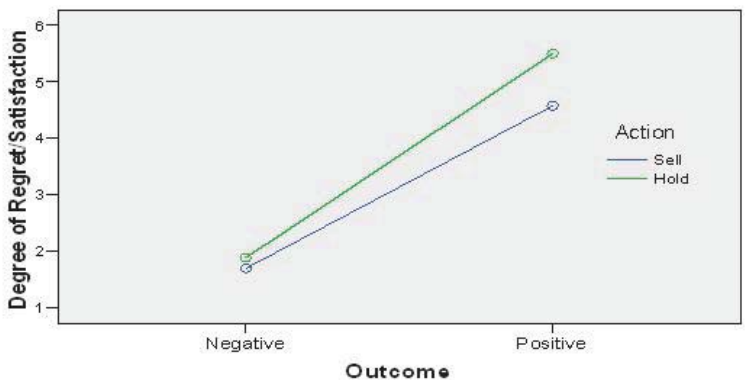

Figure 1. Ordinal Interaction

Meanwhile, Figure 2 shows the disordinal interaction of factors on experiential thinking style. Therefore, in the experiential thinking style, the main effect can not be interpreted independently of the interaction of two factors, namely the type of action and decision outcome. Based on Table 2 and Figure 2 show that when participants have experiential thinking style and decision outcome is negative (actual loss), the degree of regret is more intense on holding stocks (1.57) than selling losing stocks $(2,36)$. Likewise, when the participants have experiential thinking style and decision outcome is positive, the 
degree of satisfaction is greater for holding (6.39) than selling gaining stocks (4.81). These results reveal that when the stock condition is a missed loss, the degree of satisfaction is greater when the action is to hold stock rather than sell gaining stoks.

\section{Experiential Style}

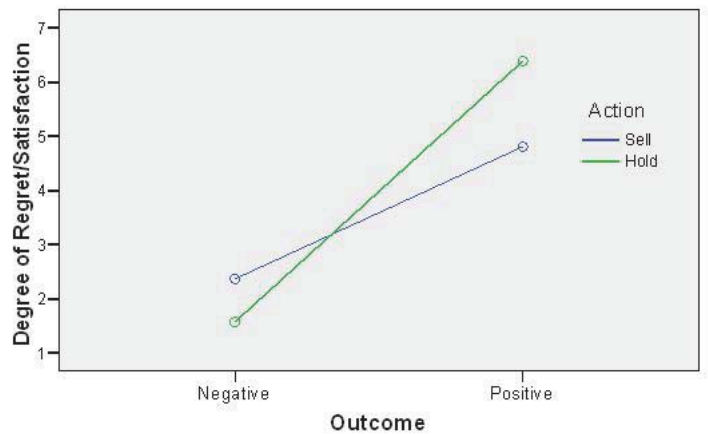

Figure 2. Disordinal Interaction

\subsection{Discussion}

The result of the analysis of the three-way factorial analysis of variance shows that there is a significant interaction of the information processing styles, types of action, and decision outcomes $(F=8.669$ and $p$-value $=0.004)$ in shaping the degree of participant's regret/satisfaction in investment decisions. This result supports hypothesis $\mathrm{H}_{1}$. This result shows that the interaction between type of action and decision outcome changes at different level of the information processing styles. When decision outcome is positivel (actual gain) and type of action is to sell stocks, degree of satisfaction is higher for participants who are in the experiential style rather than rational styles. On the contrary, when decision outcome is positive (missed loss) and type of action is to hold stocks, degree of satisfaction is higher for participants who have an experiential style rather than a rational style. This result supports hypothesis $\mathrm{H}_{1 a}$. Likewise, when the decision outcome is negative (actual loss) and type of action is hold losing stock, degree of regret is higher for participants who are in the experiential styles rather than rational styles. However, when the decision outcome is negative (missed gain) and type of action is hold losing stock, degree of regret is lower for participants who are in experiential styles rather than rational styles. This result supports the hypothesis $\mathrm{H}_{1 b}$.

As expected, the experimental results indicate that the emotion of regret/satisfaction in investment decisions is more predominant in participants who are in the experiential thinking style than rational thinking style. Accordingly, the level of investor's disposition error is higher in experiential style than in rational style. In this case, the level of investor's disposition error depends on the antecedents of the emotion of regret. Emotion of regret stems from interaction of types of outcome, types of action, and information processing styles. In this regard, experience and anticipation of emotion of regret leads investor to the higher level of disposition error (Shefrin \& Statman, 1985). This result reveals that investor's disposition error as a result of the fear of the emotions of regret. This statement is also supported by the result of this study that the main effect of the information processing styles is significant $(F=11.529$; $p$-value $=0.001)$. This means that there is a mean difference between the rational thinking style and experiential thinking style. The result of this study supports hypothesis $\mathrm{H}_{2}$.

In addition, the result of this study indicates that subjects who are in a rational thinking style and decision outcome is negative, degree of their regret is more intense due to sell rather than hold losing stock. This result suggests that the degree of regret is more intense due to selling missed gain rather than hold actual loss. Moreover, subjects who are in a rational thinking style and decision outcome is positive, degree of their satisfaction is greater due to hold missed loss rather than sell gaining stock. This result reveals that when the stock condition is a missed loss, the degree of satisfaction is greater when the action is to hold stock rather than sell stoks. The high degree of satisfaction indicates that the level of participant's disposition error is lower when holding the stock. These results support the predictions of the hypothesis $\mathrm{H}_{2}$.

Likewise, the results of study show that subjects who are in an experiential thinking style and decision outcome is 
negative, degree of their regret is more intense due to hold rather than sell losing stock. This result also reveals that when the stock condition is an actual loss, the degree of regret is more intense when holding stocks rather than sell stocks. Moreover, subjects who are in an experiential thinking style and decision outcome is positive, degree of their satisfaction is greater due to hold missed loss rather than sell gaining stock. This result reveals that when the stock condition is a missed loss, the degree of satisfaction is greater when the action is to hold stock rather than sell gaining stoks. The high degree of satisfaction indicates that the level of participant's disposition error is higher when holding the stock. These results are consistent with the predictions of the hypothesis $\mathrm{H}_{2}$.

Overall, the emotion of regret/satisfaction in investment decisions is more predominant in participants who are in the experiential thinking style than rational thinking style. This result indicates that the level of disposition error is greater in participants who are in experiential thinking style than rational thinking style. This happens because the investor in making his decision is more based on feelings. This condition can be misleading investor in the omission bias. Instead, the rational thinking style lead investors to make a decision based on the analysis and they can control their emotions so that the level of disposition error decreased (Slovic et al., 2004). However, in this study the level of disposition error is not reduced completely.

\section{Conclusion, Limitations and Future Research}

\subsection{Conclusion}

Based on the experimental results it can be concluded several important findings as follow. First, the results of the analysis of the three-way factorial analysis of variance show that there is a significant three-way interaction of the information processing styles, types of action, and decision outcomes in shaping the degree of participant's regret/satisfaction in investment decisions. Interestingly, when decision outcome is positive (missed loss) and type of action is to hold stocks, degree of satisfaction is higher for participants who are in an experiential rather than rational styles. Likewise, when the decision outcome is negative (actual loss) and type of action is hold losing stock, degree of regret is higher for participants who are in an experiential styles rather than a rational styles.

Second, the result of this study indicates that subjects who are in a rational thinking style and decision outcome is negative, degree of their regret is more intense due to sell rather than hold losing stock. Moreover, subjects who are in a rational thinking style and decision outcome is positive, degree of their satisfaction is greater due to hold missed loss rather than sell gaining stock. Likewise, the result of study show that subjects who are in an experiential thinking style and decision outcome is negative, degree of their regret is more intense due to hold rather than sell losing stock. Also, subjects who are in an experiential thinking style and decision outcome is positive, degree of their satisfaction is greater due to hold missed loss rather than sell gaining stock.

\subsection{Limitations, and Future Research}

The study has limitations. First, the measurement of the emotional consequences of regret is only limited to the consequences of investor's disposition error. Future research should not only consider the consequences of disposition error, but also the financial consequences. Second, future research not only focuses on the state variable, but also considers another aspects of individual differences or investor personality trait, such as locus of control. Third, future research could also directly measure factors affecting disposition error such as responsibility and self-regulation. However, this study is the experimental study; and thus, for future research through surveys and in-depth interviews should be conducted.

\section{References}

Ackert, L. Church, B.K. \& Deaves, R. (2003). Emotion and Financial Markets.Economic Review, 2003: 33-4.

Bell, D.E. (1982). Regret in Decision Making Under Uncertainty. Operation research, 30, 961-981.

Chui, P.M.W. (2001). An Experimental Study of The Disposition Effect: Evidence From Macau. Journal of Psychology and Financial Markets, 2(4), 216-222.

Connolly, T. (2004). Decision Justification Theory: A New Theory of Decision Regret. Working Paper. University of Arizona.

Connolly, T. \& Zeelenberg, M. (2002). Regret in Decision Making". American Psychological Society, 11(6), 212-216

Epstein, S., Pacini, R., Denes-Raj, V. \& Heier, H. (1996). Individual Difference in Intuitive-Experiential And Analytical Rational Thinking Styles. Journal of Personality and Social Psychology, 71(2), 390-405.

Fogel, S. O. \& Berry, T. (2006).The Disposition Effect and Individual Investor Decisions: The Roles of Regret and Counterfactual 
Alternatives. Journal of Behavioral Finance, 7(2),107-116.

Frazzini, A. (2006). The Disposition Effect and Under-reaction to News. Journal of Finance, 61(4), 2017-2046.

Gul, F.A. (1984). The Joint of Moerating Role of Personality and Cognitive Style on Decision Making. The Acounting Review, 59 (2), 264277.

Hon-snir, S., Kudryavtsev, A., \& Cohen, G. (2012). Stock Market Investors: Who Is More Rational, and Who Relies on Intuition?. International Journal of Economic and Finance, 4(5), 56-72.

Kahneman, D., \& Tversky, A. (1982). The Psychology of Preference. Scientific American, 246, 167-173.

Keppel, G. (1982). Design and Analysis: A Researcher's Handbook. Berkeley: Department of Psychology University of California.

Krishnan, R. \& Booker, D.M. (2002). Investors' Use of Analysts Recommendations. Behavioral Research In Accounting, 14, 129-156.

Loomes, G., \& Sugden, R. (1982). Regret Theory: An Alternative Theory of Rational Choice Under Uncertainty. Economic Journal, 92, 805-824.

Myers, A. \& Hans, C.H. (2001). Experimental Psychology. USA: Wadsworth, Thomson Learning.

Nofsinger, J.R. (2002). The Psychology of Investing. New Jersey: Prentice Hall.

Odean, T. (1998). Are Investors Reluctant to Realize Their Losses? Journal of Finance,53 (5), 1775-1797.

Pacini, R. \& Epstein, S. (1999). The Relation of Rational and Experiential Information Processing Styles to Personality, Basic Beliefs, and The Ratio Bias Phenomenon". Journal of Personality and Social Psychology, 76 (6), 972-987.

Pacini, R. Muir, F. \& Epstein, S. (1998). Depressive Realism From the Perspective of Cognitive-Experiential Self-Theory. Journal of Personality and Social Psychology, 74 (4): 1056 -1068.

Richard, F. \& Lei, W. 2011.Managerial ownership and the DispositionEffect. Journal of Banking \& Finance, 35(9): 2407-2417

Shefrin, H. \& Statman, M. (1985). The Disposition to Sell Winners Too Early and Ride Losers Too Long: Theory and Evidence". Journal of Finance, 40(3), 777-790.

Slovic, P., Finucane, M., Peter, E., \& MacGregor, (2004). Risk as Analysis and Risk as Feelings: Some Thoughts About Affect, Reason, Risk, and Rationality. Risk Analysis, 24 (2), 311-322.

Talpsepp, T. 2011. Reverse Disposition Effect of Foreign Investtor. Journal of Behavior Finance, 12: $183-200$.

Tehrani, R. \& Gharehkoolchian, N. (2012). Factors Affecting the Disposition Effect in Tehran Stock Market. International Business Research, 5(3), 40-45.

Todd, F. (2012). The Most Destructive Behavioral Bias. Journal of Investing, 21 (2), 49-56.

Zeelenberg, M., Van den Bos, K., van Dijk, E., \& Pieters, R. (2002). The Inaction Effect in the Psychology of Regret. Journal of Personality and Social Psychology, 82(3), 314-327. 